\title{
Use of PCR-mediated amplification of Mycobacterium leprae DNA in different types of clinical samples for the diagnosis of leprosy
}

\author{
A. R. SANTOS, A. B. DE MIRANDA*, E. N. SARNO, P. N. SUFFYS* and W. M. DEGRAVE* \\ Department of Tropical Medicine—Leprosy Sector and *Department of Biochemistry and Molecular Biology, \\ Oswaldo Cruz Foundation, Av. Brasil 4365, Manguinhos 21045-900, Rio de Janeiro, RJ, Brazil
}

\begin{abstract}
Summary. DNA of Mycobacterium leprae, obtained by a highly efficient nucleic acid extraction procedure, was used for standardisation of the amplification of an $M$. lepraespecific repetitive sequence by use of the polymerase chain reaction (PCR). With pure DNA, $M$. leprae-specific amplification was obtained with as low as $100 \mathrm{ag}\left(1 \mathrm{ag}=10^{-18} \mathrm{~g}\right)$ of target DNA, a quantity equal to about one-tenth of the bacterial genome. Optimal processing of different types of clinical samples such as biopsy material, blood and lymph fluid, from multibacillary leprosy patients, was studied. Simple freezing-boiling cycles in the presence of Triton X100, with some additional sample-specific modifications such as pre-treatment with $\mathrm{NaOH}$ to eliminate PCR inhibitors, was found to be sufficient to yield amplification of bacterial DNA in samples from paucibacillary patients. Clinical samples from 27 untreated leprosy patients, covering the various clinical forms of the disease, and with a bacterial index ranging from $5+$ to 0 , were collected and processed for PCR analysis. After hybridisation of the amplified material with a specific sequence, 25 of 27 patients analysed gave positive results for M. leprae in at least one of the samples. The potential of PCR for the diagnosis of leprosy is discussed.
\end{abstract}

\section{Introduction}

Identification of Mycobacterium leprae is difficult, partly due to the inability of the leprosy bacillus to grow in vitro. The diagnosis of leprosy is based on microscopic detection of acid-fast bacilli in tissue smears, in combination with histopathological and clinical evaluation. Recently, the use of various serological and biochemical methods or the use of nucleic acid probes has been suggested for diagnosis. ${ }^{1}$ However, none of these has shown sufficient sensitivity or specificity to serve as a diagnostic tool for leprosy.

In the last few years, several reports on the use of the polymerase chain reaction (PCR) for detection of $M$. leprae have been published. ${ }^{2-7}$ The strength of PCR is its extreme sensitivity, and, with careful choice of primers, high specificity. For specific amplification of $M$. leprae DNA, the following systems were developed. Woods et al..$^{2}$ detected small numbers $\left(10^{2}\right)$ of bacteria by amplifying an $M$. leprae-specific repetitive sequence. A similar number of bacilli could be detected by Williams et al., ${ }^{5}$ by amplification of a large part of the gene coding for the $18-\mathrm{kDa}$ antigen. Hartskeerl et al. ${ }^{3}$ were able to detect DNA from a few bacteria by amplification of part of the coding sequence of the 36$\mathrm{kDa}$ antigen. Plikaytis et al. ${ }^{4}$ detected as little as $3 \mathrm{fg}$ of

Received 27 Oct. 1992; accepted 18 March 1993.
M. leprae genomic DNA by use of nested primer PCR of a portion of the groEL gene.

PCR has already been used successfully for the detection of a large number of micro-organisms present in diverse tissues, ${ }^{8}$ including the diagnosis of tuberculosis, a mycobacterial disease caused by $M$. tuberculosis, by applying PCR to different types of clinical samples. ${ }^{9}$ Although the specificity and sensitivity of most systems used for detection of $M$. leprae is high, thus far data have been presented only on the application of PCR to human skin samples reconstituted with $M$. leprae ${ }^{2.4 .5}$ or to biopsy samples from leprosy patients. ${ }^{7,10}$ As biopsy sampling is invasive for the patient and skin lesions cannot always be found, we investigated whether clinical samples other than biopsy material could be used for the diagnosis of leprosy. For this purpose, we used PCR amplification of an $M$. leprae-specific repetitive sequence as described by Woods and Cole. ${ }^{2}$

\section{Materials and methods}

\section{Bacterial strains and culture conditions}

M. tuberculosis strains $\mathrm{H}_{37} \mathrm{Rv}$ and $\mathrm{H}_{37} \mathrm{Ra}$ (a gift from Dr A. Werneck, Tuberculosis Reference Center Prof. Helio Fraga, RJ, Brazil) and M. bovis-BCG 
(kindly provided by the Ataulfo de Paiva Foundation, RJ, Brazil) were grown in Middlebrook 7H9 broth (Difco) at $37^{\circ} \mathrm{C}$ for 21 days. $M$. smegmatis ATCC 19420, M. avium ATCC 25291 and $M$. kansasii ATCC 12478 were grown in Roux bottles containing $400 \mathrm{ml}$ of Sauton medium at $37^{\circ} \mathrm{C}$ for $17-20$ days. M. szulgai NCTC 10831 was grown in the same conditions for 27 days. After growth, bacterial suspensions were centrifuged and the pellet was stored at $-20^{\circ} \mathrm{C}$ until required. All species were also grown on LowensteinJensen medium (Difco) and stored at $4^{\circ} \mathrm{C} . M$. leprae was purified from infected armadillo tissue as described previously. ${ }^{11}$

\section{Preparation of DNA}

Mycobacterial DNA was prepared and purified as described previously. ${ }^{12}$ Briefly, cells were mixed with glass beads, phenol and TE-buffer $(10 \mathrm{~mm}$ Tris- $\mathrm{HCl}$, $1 \mathrm{~mm}$ EDTA, pH 7.0) and disrupted by vortex mixing for $3 \mathrm{~min}$. The suspension was submitted to chemical lysis with sodium deoxycholate, followed by deproteinisation of nucleic acids with phenol:chloroform (1:1). M. leprae DNA was prepared in the laboratory of Dr M. J. Colston (National Institute of Medical Research, London), by a slightly modified procedure for large scale DNA preparation. ${ }^{12}$ In summary, frozen bacilli were disrupted in a cooled mortar with glass beads, followed by the addition of sodium deoxycholate and potassium perchlorate. Subsequent chloroform extraction and DNA precipitation yielded pure nucleic acid. After drying, DNA was dissolved in TE-buffer.

Human DNA was prepared from peripheral blood mononuclear cells (PBMC). After separation from whole blood by Ficoll-Hypaque (Sigma) PBMC were incubated overnight with sarcosyl (Sigma) $0.03 \%$ and proteinase $\mathrm{K}$ (Boehringer Mannheim, Mannheim, Germany) $0.4 \mathrm{mg} / \mathrm{ml}$ at $55^{\circ} \mathrm{C}$. DNA was purified by phenol-chloroform extraction and ethanol precipitation.

\section{PCR amplification}

For the amplification of the $M$. leprae-specific repetitive sequence, a set of primers was synthesised: ML-1 (GCACGTAAGCCTGTCGGTGG) and ML-2 (CGGCCGGATCCTCGATGCAC), according to Woods and Cole. ${ }^{2}$ Oligonucleotides were synthesised in our laboratory by means of an automated DNA synthesiser model 381A (Applied BioSystems, ABI, Foster City, USA), with $\beta$-cyanoethyl phosphoramidite chemistry. Oligonucleotides were purified by use of TLC or on Oligonucleotide Purification Cartridges (OPC; $\mathrm{ABI})$.

All PCR amplifications were performed in a Thermal Cycler model 480 (Perkin-Elmer-Cetus, Norwalk, CT, USA). A given quantity of template DNA (10 ng in most experiments) was mixed with $200 \mathrm{ng}$ of each primer, $1 \mathrm{U}$ of Taq polymerase (Ampli-Tac, Perkin-
Elmer-Cetus), $200 \mu \mathrm{M}$ of each deoxynucleotide triphosphate (stock solution $5 \mathrm{~mm}, \mathrm{pH} 8.3$ ), $10 \mathrm{~mm}$ Tris- $\mathrm{HCl}$ (pH 8.3), $50 \mathrm{~mm} \mathrm{KCl}, 1.5 \mathrm{mM} \mathrm{MgCl}_{2}$, gelatin $0.01 \%$ and water to a final volume of $50 \mu \mathrm{l}$. The mixture was overlaid with $50 \mu \mathrm{l}$ of mineral oil (PerkinElmer-Cetus), and samples were held at $92^{\circ} \mathrm{C}$ for $3 \mathrm{~min}$ to denature chromosomal DNA, followed by 30 or 45 cycles of $2.5 \mathrm{~min}$ at $55^{\circ} \mathrm{C}, 2 \mathrm{~min}$ at $72^{\circ} \mathrm{C}$ and $1.5 \mathrm{~min}$ at $92^{\circ} \mathrm{C}$, and a final extension cycle at $72^{\circ} \mathrm{C}$ for $7 \mathrm{~min}$. Samples were analysed by gel eletrophoresis in an agarose $3 \%$ : Nusieve gel $(1: 2$; purchased from Sigma and FMC Bioproducts, Oakland, USA, respectively). DNA in the gel was visualised by ethidium bromide staining.

\section{DNA transfer and Southern hybridisation}

An oligonucleotide ML-97 (TTTTAGTGTG CATGTCATGG), complementary to the amplified fragment of the repetitive sequence, or a 742-bp Bss HII fragment containing part of the repetitive sequence (obtained from a plasmid containing the gene coding for the $65-\mathrm{kDa}$ antigen and part of its $3^{\prime}$ flanking sequence, ${ }^{13}$ kindly provided by Dr B. Jacobs, Albert Einstein College of Medicine, NY, USA) was used for hybridisation. DNA was denatured by soaking the gel in $0.4 \mathrm{~N} \mathrm{NaOH}$ for $10 \mathrm{~min}$, and transferred to a nylon membrane (Zeta-Probe, BioRad, Richmond, USA) overnight by alkaline capillary blotting. Membranes were pre-hybridised for $3 \mathrm{~h}$ in $6 \times$ SSPE $(20 \times$ SSPE is $3.6 \mathrm{M} \mathrm{NaCl}, 200 \mathrm{~mm} \mathrm{NaH} \mathrm{PO}_{4}$ and $20 \mathrm{~mm}$ EDTA, pH 7.4), $5 \times$ Denhardt's solution and SDS $0.5 \%$ at $45^{\circ} \mathrm{C}$. When the 742 -bp fragment was used as a probe, formamide $50 \%$ was added to the solution. Membranes were hybridised overnight at $42^{\circ} \mathrm{C}$ in the same solutions, adding $10^{6} \mathrm{cpm} / \mathrm{ml}$ of either the oligonucleotide that was radiolabelled with ${ }^{32} \mathrm{P}$-ATP (ICN Inc., Irvine, USA) to a specific activity of $2 \times 10^{7} \mathrm{cpm} / \mu \mathrm{g},{ }^{14}$ or the 742 -bp fragment that was ${ }^{32} \mathrm{P}$ labelled by random priming, to a specific activity of $6 \times 10^{7} \mathrm{cpm} / \mu \mathrm{g} .{ }^{14}$ All membranes were washed with $2 \times \operatorname{SSPE}$ and SDS $0.1 \%$ at $42^{\circ} \mathrm{C}$ for $30 \mathrm{~min}$; a second washing for the same period was carried out either in the same solution at $55^{\circ} \mathrm{C}$ (oligonucleotide), or in $0.5 \times$ SSPE and SDS $0.1 \%$ at $68^{\circ} \mathrm{C}$ (742-bp fragment).

\section{Collection and processing of clinical samples for PCR}

Minute fractions of blood, lymph and biopsy material, initially from multibacillary, and later also from paucibacillary, untreated leprosy patients, were collected in the Souza Araujo ambulatory of the Oswaldo Cruz Foundation as part of the normal diagnostic routine. ${ }^{15,16}$ All patients were clinically well defined and the bacillary index (BI) and morphological index (MI) in biopsy and lymph samples was determined. For PCR analysis, fractions of the original samples were further processed as follows: a small piece (about $1 \mathrm{~mm}^{3}$ ) of biopsy material was incubated with $50 \mu$ of $0.5 \mathrm{~N} \mathrm{NaOH}$ at room temperature for 


\section{$1234567891011 \quad 1234567891011$}

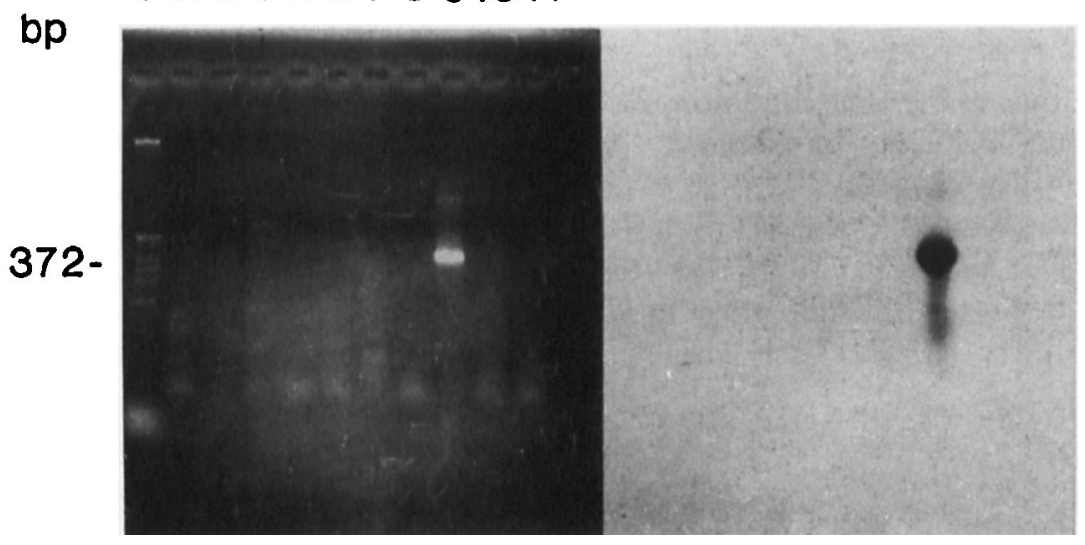

Fig. 1. $M$. leprae-specific amplification (30 cycles) as shown by visual (A) and hybridisation (B) analysis. Lane 1, pBR322-Hinf I; 2 , 10 ng of purified DNA from $M$. szulgai; 3, M. bovis-BCG; 4, M. kansasii; $5, M$. tuberculosis $\mathrm{H}_{37} \mathrm{Ra} ; 6, M$. tuberculosis $\mathrm{H}_{37} \mathrm{Rv} ; \mathbf{7}, M$. smegmatis; 8 , $M$. avium; $9, M$. leprae; 10, human DNA; 11 , a negative control without target DNA. B, Amplified material was hybridised with the 742 -bp fragment containing the $M$. leprae specific repetitive sequence.

10 min with occasional mixing, neutralised with $1 \mathrm{M}$ $\mathrm{NaH}_{2} \mathrm{PO}_{4}$, centrifuged, and the supernate was removed. Further treatment was done with two different protocols. In protocol I, modified from Hermans et al. ${ }^{6}$ the pellet was resuspended in $50 \mu$ of a solution of $50 \mathrm{mM}$ Tris- $\mathrm{HCl}$ and $5 \mathrm{mM}$ EDTA (pH 8.0), incubated with lysozyme (Sigma) $1 \mathrm{mg} / \mathrm{ml}$ for $90 \mathrm{~min}$ at $37^{\circ} \mathrm{C}$, and followed by incubation with proteinase $\mathrm{K}$ $1 \mathrm{mg} / \mathrm{ml}$ and SDS $1 \%$ for $30 \mathrm{~min}$ at $60^{\circ} \mathrm{C}$ and stored at $4^{\circ} \mathrm{C}$. In protocol II, adapted from Sritharan et al., ${ }^{17}$ the pellet obtained as described above was resuspended in $50 \mu \mathrm{l}$ of TE-buffer containing Triton X100 1\% (TETriton), and stored at $4^{\circ} \mathrm{C}$. After initial processing and before testing in PCR, both types of samples were submitted to a thermic shock precedure, consisting of three consecutive cycles of $10 \mathrm{~min}$ boiling and snapfreezing. Samples were then stored at $-20^{\circ} \mathrm{C}$.

Blood $(1.5 \mathrm{ml})$ was mixed with the same volume of phosphate-buffered saline (PBS; pH 7.2), after which PBMC were isolated on a Ficoll-Hypaque density gradient (Sigma). Isolated PBMC were washed twice with PBS, pre-treated with $0.25 \mathrm{~N} \mathrm{NaOH}$, neutralised with $1 \mathrm{M} \mathrm{NaH}_{2} \mathrm{PO}_{4}$, centrifuged, resuspended in $40 \mu \mathrm{l}$ of TE-Triton, and submitted to thermic shock as described above.

Lymph ( 1 or $2 \mu \mathrm{l}$ ), collected from the ear lobe, was mixed with $40 \mu \mathrm{l}$ of TE-Triton and submitted to the thermic shock procedure as described above.

\section{Results}

\section{Specificity of amplification of $M$. leprae DNA}

With experimental conditions similar to those of Woods and Cole, ${ }^{2}$ purified DNA from $M$. leprae, from seven other species of mycobacteria, and human DNA was submitted to PCR amplification. Only DNA from $M$. leprae gave the expected amplification product of
$372 \mathrm{bp}$ (fig. 1A). Amplified DNA was hybridised with the oligonucleotide probe ML-97, and, as shown in fig. 1B, hybridisation of the probe occurred only with amplified $M$. leprae DNA. In some experiments, a slight non-specific background amplification of human DNA was obtained; however, no hybridisation signals were found with this amplification product (data not shown).

\section{Sensitivity of the PCR assay}

Samples from a serial dilution of $M$. leprae DNA were added to the PCR reaction mixture and amplified during 45 cycles. Staining of amplified material with ethidium bromide revealed a detection limit of $100 \mathrm{ag}$ (fig. 2). Given that the size of the $M$. leprae genome is $2.2 \times 10^{9} \mathrm{Da},{ }^{18} 100 \mathrm{ag}$ of DNA corresponds to $c$. onetenth of the bacterial genome.

\section{Amplification of $M$. leprae DNA in clinical samples from multibacillary leprosy patients}

Four pieces of a skin biopsy from a patient with multibacillary leprosy and three pieces from a patient with a non-leprosy dermatosis (polymorphous light eruption) were processed by two different protocols as described in Materials and methods, and submitted to amplification by PCR involving 30 and 45 cycles. Fig. 3 clearly shows that the protocol with lysozymeproteinase K-SSD, followed by thermic shock, was less efficient than submitting the biopsy material to thermic shock in the presence of Triton X100 1\%. Also, the non-specific amplification of human DNA was less after processing with the latter protocol. Hybridisation of the oligonucleotide probe or the 742-bp fragment occurred only with amplified DNA from infected patients (data not shown). As thermic shock in the presence of a small amount of Triton X100 gave 


\section{$\begin{array}{lllllll}1 & 2 & 3 & 4 & 5 & 6 & 7\end{array}$}

$b p$

372-

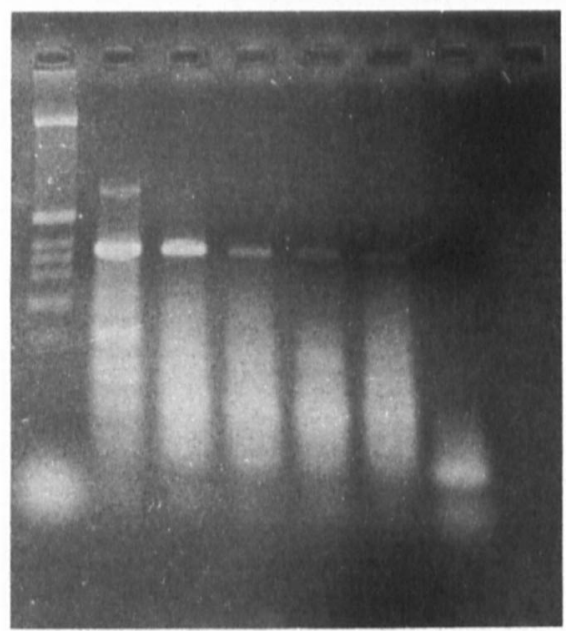

Fig. 2. PCR amplification (45 cycles) of a dilution of purified $M$. leprae DNA. Lane 1, pBR322-Hinf I as a mol. wt marker; 2 , $10 \mathrm{ng}$ of DNA;3,100 pg; 4, $100 \mathrm{fg} ; 5,1 \mathrm{fg} ; 6,100 \mathrm{ag} ; 7$, a negative control without target DNA.

\section{$\begin{array}{llllllll}123 & 5 & 5 & 78\end{array}$}

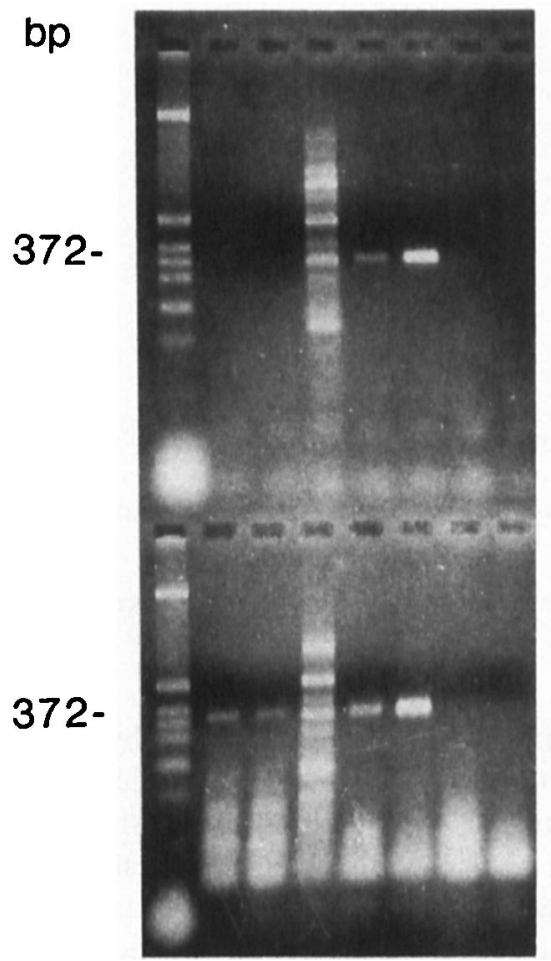

A

B

Fig. 3. Specific amplification of $M$. leprae DNA in a biopsy sample from a multibacillary leprosy patient (2A-B, 3A-B, 5A-B and 6A-B) and a patient with polymorphous light eruption (4A-B, 7A-B and 8A-B), after processing of the biopsies with protocol I (2A-B, 3A-B and 4A-B) or protocol II (5A-B, 6A-B, 7A-B and 8A-B). Lane 1: pBR322-Hinf I mol. wt marker. Five $\mu$ l of processed material was submitted to amplification for 30 (A) or 45 (B) cycles.

satisfactory results, and this treatment has been reported to function in other PCR systems, ${ }^{16}$ it was applied to other types of clinical samples.

After thermic shock treatment of PBMC, isolated from $1.5 \mathrm{ml}$ of blood from an LL patient and from one normal control, one-twentieth of the material was amplified through 45 cycles. Lymph, collected
A

B

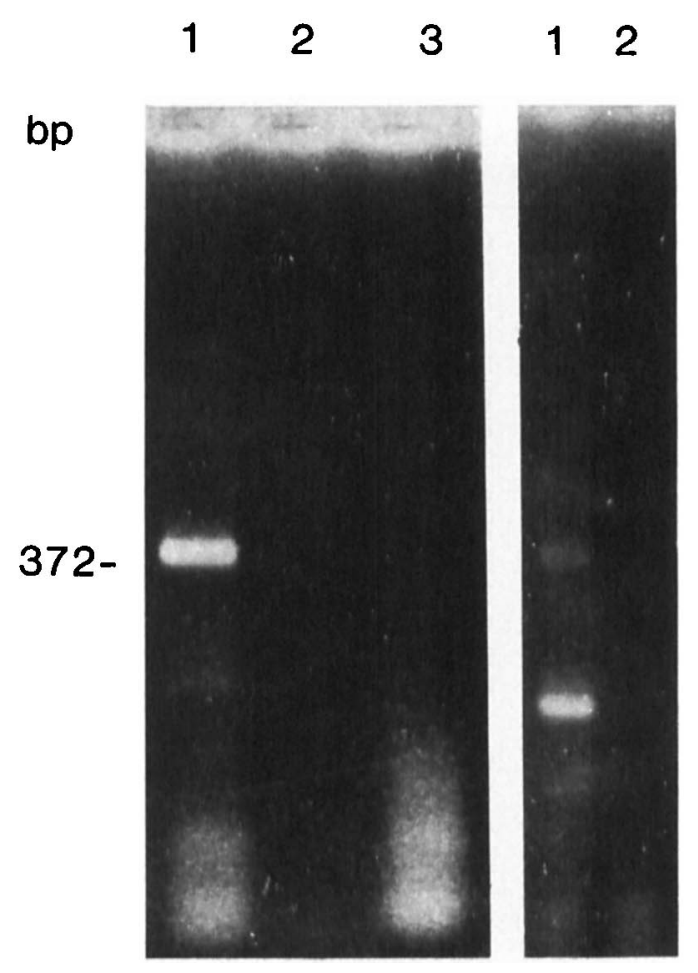

Fig. 4. Specific amplification of $M$, leprae DNA in lymph (A) and PBMC (B) samples from multibacillary leprosy patients (A1 or B1) or normal donors (A2-3 or B2); $2 \mu$ l of processed PBMC (B1-2) and $1 \mu \mathrm{l}$ (A1-3) of lymph were submitted to 45 cycles of PCR.

from the ear lobe of a patient with multibacillary leprosy and from two normal controls, was submitted to thermic shock, and one-fiftieth and one-tenth of this material was also amplified in this way. Although a lower mol. wt band with stronger intensity was prominent in the amplification product from bloodderived material, amplification of the 372-bp fragment was clearly visible in the sample from the leprosy patient (fig. 4B). After blotting, the probes hybridised only with the 372-bp fragment of the amplified sample from leprosy patients. In contrast to the results obtained with blood samples, only a 372-bp product was detected after amplification of lymph material. As with PBMC, hybridisation experiments were positive only for amplified material from leprosy patients (data not shown). Surprisingly, no amplification product was seen with $5 \mu$ l of lymph solution. Reconstitution experiments with purified $M$. leprae DNA revealed that final Triton X100 concentrations of $>0.04 \%$ strongly inhibited amplification. Unrelated to the action of Triton X100, thermic shock-treated PBMC also inhibited PCR amplification. However, a simple pre-treatment with $\mathrm{NaOH}$, as described above, neutralised this inhibitory activity and allowed the use of $5 \mu \mathrm{l}$ of processed PBMC in the PCR mixture.

\section{Diagnosis of leprosy}

The presence of $M$. leprae in biopsy material, blood 
Table. Diagnosis of leprosy in patients with different clinical forms of the disease by PCR and subsequent hybridisation detection

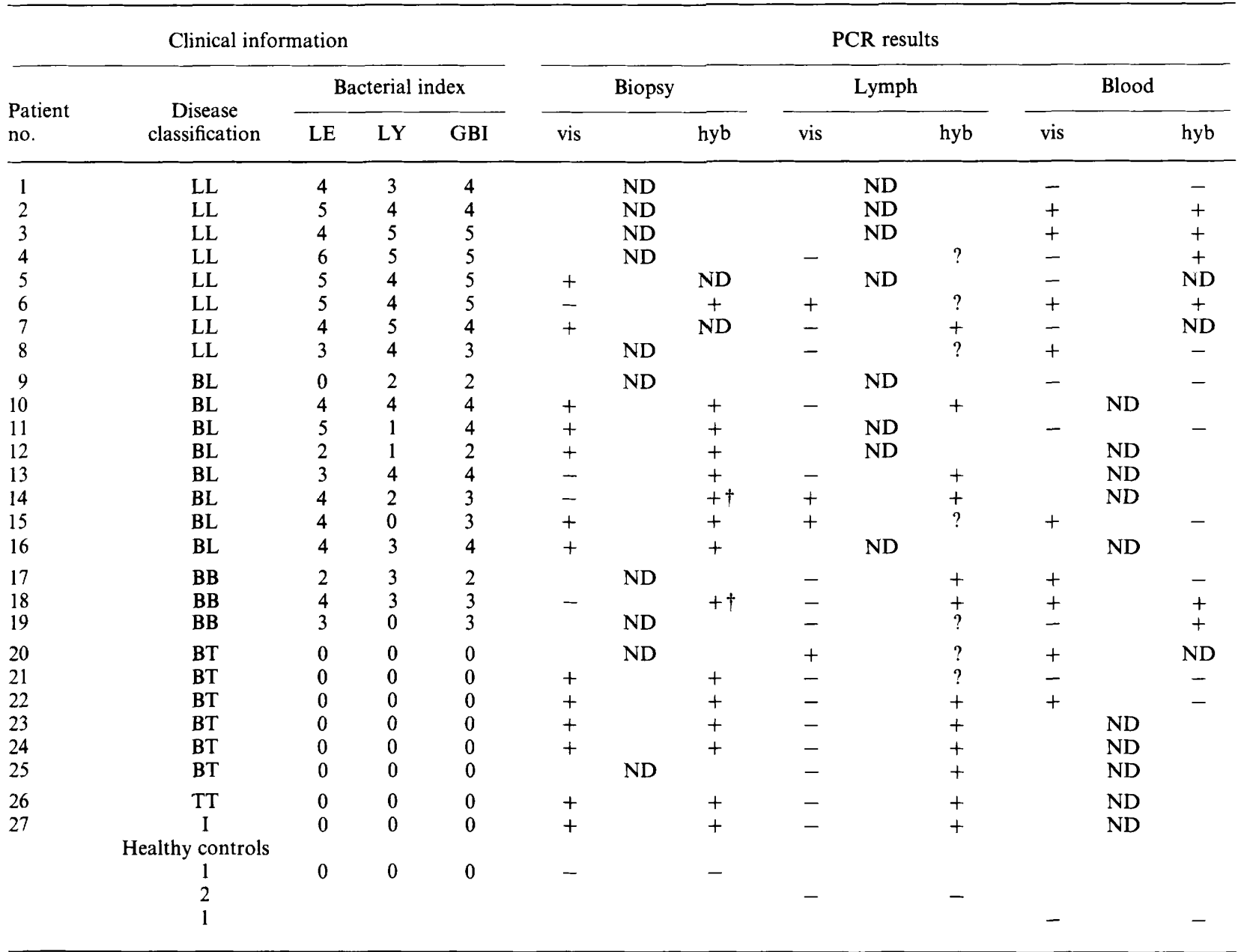

LL, lepromatous leprosy; BL, borderline lepromatous leprosy; BB, borderline leprosy; BT, borderline tuberculoid leprosy; TT, tuberculoid leprosy; I, indeterminate leprosy.

The bacterial index was determined in the lesion biopsied (LE), in the lymph (LY) and as the mean value of six sites, the general bacterial index (GBI).

ND, not determined.

+ , positive; - , negative; ?, doubtful; vis, by direct visualisation of a product by ethidium bromide staining; hyb, by Southern hybridisation.

$\dagger$ These results were initially negative but were subsequently found to be positive after an additional DNA extraction.

or lymph samples from a total of 27 untreated leprosy patients with various forms of the disease was analysed. Eight lepromatous leprosy (LL) patients, eight borderline lepromatous $(\mathrm{BL})$ patients, three borderline leprosy (BB) patients, six borderline tuberculoid (BT) patients, one tuberculoid (T) and one indeterminate (I) patient, classified according to the Ridley and Jopling scale, ${ }^{19}$ were included in the study. Samples were processed and submitted to PCR, followed by both visual and hybridisation analysis of the amplified material (table). PCR of samples from normal donors or patients with non-leprosy skin diseases (polymorphous light eruption or discoid lupus erithematosus) gave negative results in all experiments. Amplified material was hybridised with the internal oligonucleotide M1-97 or with the 742-bp fragment, or both, and results were considered to be positive when at least one gave a hybridisation signal.

All but two patients from whom biopsy material was amplified were found to give positive results after
PCR amplification-13 (76\%) of 17 by visual detection; $13(87 \%)$ of 15 by hybridisation. The two negative samples were subsequently shown to be positive after PCR of the DNA extracted from the biopsy material with a very efficient but somewhat laborious extraction protocol for mycobacterial DNA, described earlier. ${ }^{12}$ Several lymph samples, although negative upon visual evaluation (positivity 4 of 19 , $21 \%$ ), were positive after hybridisation (13 of 19 , $68 \%$ ). In some of these experiments ( 6 of 19 ), a faint hybridisation signal was observed with the mol. wt marker when the 742-bp fragment was used as a probe. When this occurred, hybridising samples were not considered to be positive. Results obtained with blood samples were sometimes difficult to evaluate. Overall positivity-9 $(53 \%)$ of 17 by visual detection; 6 ( $43 \%)$ of 14 by hybridisation-in blood samples was lower than that found in other samples; also, some samples which seemed positive by visual evaluation, did not show any hybridisation signal. 
A

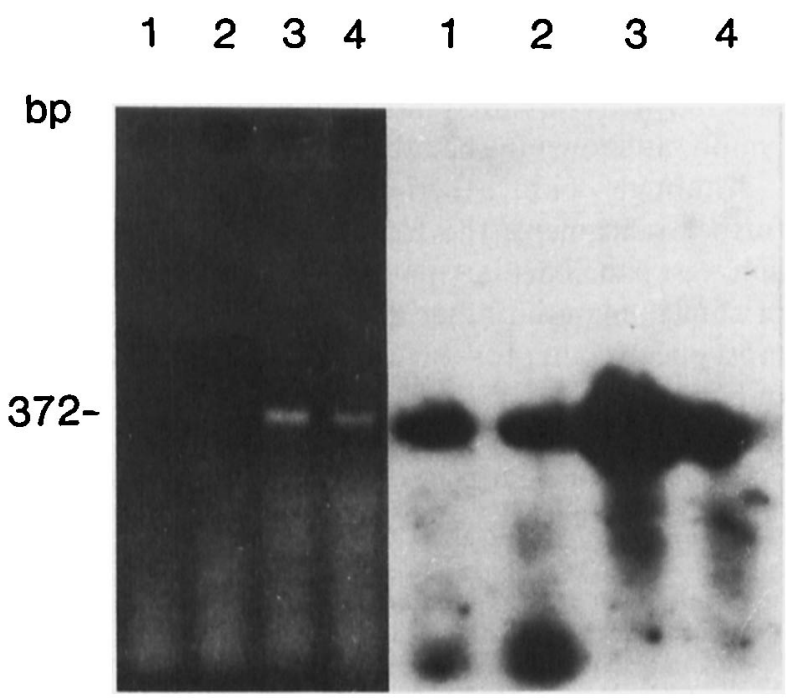

Fig. 5. Amplification of $M$. leprae DNA in processed biopsies from a BB leprosy patient (lanes 1 and 2) and from a BL leprosy patient ( 3 and 4 ). Either $5 \mu \mathrm{l}(1$ and 3 ) or $1 \mu \mathrm{l}(2$ and 4 ) were submitted to 45 cycles of PCR and analysed visually $(\mathbf{A})$ or after hybridisation with the 742-bp fragment (B).

\section{Discussion}

One of the first reports on the use of PCR as a potential tool for diagnosis of leprosy described an $M$. leprae-specific repetitive sequence as a target for amplification. ${ }^{2}$ Because of the high number of copies of this repetitive sequence present in the genome, and because of the specificity of this PCR system, the amplification conditions were optimised and the applicability of this system as a diagnostic tool for leprosy, with different types of clinical samples was investigated. To eliminate false positive results due to non-specific amplification, amplified material was hybridised with an internal probe or with a fragment of the cloned repetitive sequence. In this way, the specificity of the amplification of $M$. leprae DNA was confirmed. Forty-five cycles of PCR amplification of purified $M$. leprae DNA revealed as little as $100 \mathrm{ag}$ of target DNA, an amount equal to $c$. one-tenth of the bacterial genome. ${ }^{18}$ The sensitivity obtained here was at least 10 times higher than described previously for $M$. lepra $e^{3,4}$ and approaches the theoretical detection limit of this method.

So far, few studies have shown experimental data on PCR detection of $M$. leprae in clinical samples, amplifying only mycobacterial DNA in frozen and fixed sections of biopsy material from leprosy patients. ${ }^{710}$ As patients do not always present with lesions and detection of the leprosy bacillus in clinical material obtained by less invasive procedures is desired, we tried to extend the diagnosis of leprosy by the investigation of different types of clinical samples. Standardisation of sample processing was initiated with fragments from skin biopsies. Woods and Cole reported a simple freeze-boiling method for $M$. leprae DNA extraction and subsequent PCR, ${ }^{2}$ and recently, the addition of Triton X100 during this process was shown to induce lysis of $95 \%$ of $M$. tuberculosis bacilli. ${ }^{17}$ Treatment of biopsy fragments from LL patients with this modified protocol resulted in detection of $M$. leprae DNA after only 30 PCR cycles. Furthermore, this method was found to be more efficient than treatment of biopsy samples with lytic enzymes, a process that seems to function well for the detection of $M$. tuberculosis in sputum. ${ }^{6}$ Because of its simplicity and efficiency, the former method for processing different clinical samples was adopted, although the possibility that more efficient protocols for the detection of $M$. leprae may be found cannot be excluded. During the preparation of this manuscript, sonication was reported to be more efficient for extracting DNA from clinical samples containing M. tuberculosis then freeze-boiling processes ${ }^{20}$ however, inhibition of PCR by some components from the resulting crude lysate could be the main drawback of this procedure. Inhibition of PCR by components of various clinical samples and especially of blood has been reported, ${ }^{21}$ and has also been described for detection of $M$. leprae. We observed inhibition of amplification in experiments with PBMC but inhibitory activity could be neutralised by a simple treatment of the PBMC samples with $0.5 \mathrm{~N} \mathrm{NaOH}$. This procedure was used routinely and allowed the application of more sample material to the PCR reaction.

Although we do not consider our sample processing conditions to be fully optimised (experiments with sonication as a treatment are being examined), the value of the PCR conditions was assessed on samples from patients. Patients from the opposite poles of the leprosy spectrum were screened for the presence of $M$. leprae in at least one type of clinical sample. The number of positive results found in biopsy and lymph samples from paucibacillary patients was encouraging, and clinical material from non-leprosy donors did not yield any false positive results. Several patients in whom microscopic examination did not reveal any bacteria gave positive results with PCR. This is in agreement with results obtained by De Wit et al. ${ }^{7}$ who amplified bacterial DNA in sections of biopsy samples taken from paucibacillary and from treated leprosy patients; however, they reported the appearance of false positive results with their methodology. In the two cases in which bacteria were not detected in biopsy material, an additional extraction of the DNA from the processed biopsy sample and subsequent PCR showed the presence of $M$. leprae DNA. Also, patients with a positive bacterial index (BI) but with a morphological index (MI) of zero were found to be PCRpositive in our study. It is well established that the determination of $\mathrm{BI}$ and $\mathrm{MI}$ is variable, and that both are relatively insensitive techniques. ${ }^{22}$ Also, the correlation between morphology and viability of $M$. leprae is not universally accepted, ${ }^{23}$ and the question has arisen as to whether PCR can be positive 
after killing of bacteria and disposal of DNA from the host tissue ${ }^{24}$ Several of the untreated LL patients who gave positive results in the PCR had an MI equal to zero; however, it is highly unlikely that these patients did not harbour any viable bacteria. Whatever the relationship between positivity of PCR and viability of $M$. leprae, PCR is much more sensitive than microscopic examination for direct detection of bacilli.

Although we consider these results to be very encouraging, some experimental drawbacks still have to be resolved. Amplification of $M$. leprae in blood samples gave inferior results in comparison to those with other types of clinical material. Although the presence of bacteria in blood samples, contrary to the case with lymph and biopsy samples, was not shown by microscopical examination, it is likely that sufficient amounts of bacteria are present in blood of at least LL patients to allow PCR detection. ${ }^{25}$ The analysis of blood samples yielded some non-specific amplification products, so additional steps in the blood processing protocol will have to be developed. The cloned 742-bp fragment needs improvement as a probe. In some cases, the pBR322 Hinf I mol. wt marker gave a slightly positive signal after hybridisation with the 742-bp restriction fragment, which is probably due to some contamination of the probe preparation with plasmid. This obscured potential positive signals with lymph, as shown in the table.

Although our experimental protocol requires further refinement, the frequency of PCR positivity amongst paucibacillary patients and the successful use of clinical material other than skin biopsy samples is most encouraging for the use of PCR in the diagnosis of leprosy.

This research was supported by UNDP/World Bank/WHO Special Training Program for Research and Training in Tropical Diseases (TDR) and the CNPq. We thank Ana Teresa Dumans for culture of mycobacteria, Leila de Mendonca Lima for M. leprae preparations, Dr Jose Augusto de Costa Nery, Dr Maria Eugenia Novinski Gallo, Dr Ana Maria Malta and Nadia Christina Duppre for clinical diagnosis of the patients and the work done in the Souza Araujo ambulatory, and D. Chaves and E. C. A. Albuquerque for biopsy handling and determination of $\mathrm{BI}$ and $\mathrm{MI}$.

\section{References}

1. Clark-Curtiss JE. Benefits of recombinant DNA technology for the study of Mycobacterium leprae. Curr Top Microbiol Immunol 1988; 138: 61-79.

2. Woods SA, Cole ST. A rapid method for the detection of potentially viable Mycobacterium leprae in human biopsies: a novel application of PCR. FEMS Microbiol Lett 1989; 65: 305-310.

3. Hartskeerl RA, De Wit MYL, Klatser PR. Polymerase chain reaction for the detection of Mycobacterium leprae. J Gen Microbiol 1989; 135: 2357-2364.

4. Plikaytis BB, Gelber RH, Shinnick TM. Rapid and sensitive detection of Mycobacterium leprae using a nested-primer gene amplification assay. J Clin Microbiol 1990; 28: 1913-1917.

5. Williams DL, Gillis TP, Booth RJ, Looker D, Watson JD. The use of a specific DNA probe and polymerase chain reaction for the detection of Mycobacterium leprae. J Infect Dis 1990; 162: 193-200.

6. Hermans PWM, Schuitema ARJ, van Soolingen D et al. Specific detection of Mycobacterium tuberculosis complex strains by polymerase chain reaction. $J$ Clin Microbiol $1990 ; 28$ : 1204-1213.

7. De Wit MYL, Faber WR, Krieg SR et al. Application of a polymerase chain reaction for the detection of Mycobacterium leprae in skin tissues. J Clin Microbiol 1991; 29: 906-910.

8. Wright PA, Wynford-Thomas D. The polymerase chain reaction: miracle or mirage? A critical review of its uses and limitations in diagnosis and research. $J$ Pathol $1990 ; 162$ : 99-117.

9. Brisson-Noël A, Lecossier D, Nassif X, Gicquel B, LévyFrébault V, Hance AJ. Rapid diagnosis of tuberculosis by amplification of mycobacterial DNA in clinical samples. Lancet 1989 ; 2: 1069-1071.

10. Arnoldi J, Schlüter C, Duchrow $M$ et al. Species-specific assessment of Mycobacterium leprae in skin biopsies by in situ hybridization and polymerase chain reaction. $L a b$ Invest 1992; 66: 618-623.

11. Draper P. Cell walls of Mycobacterium leprae. Int J Leprosy $1976 ; 44: 95-98$.

12. Santos AR, De-Miranda AB, Lima LM, Suffys PN, Degrave WM. Method for high yield preparation in large and small

scale of nucleic acids from mycobacteria. $J$ Microbiol Methods 1992; 15: 83-94.

13. Mehra V, Sweetser D, Young RA. Efficient mapping of protein antigenic determinants. Proc Natl Acad Sci USA 1986; 83: 7013-7017.

14. Sambrook J, Fritsch E, Maniatis T. Molecular cloning. A laboratory manual. Second edition. Cold Spring Harbor, Cold Spring Harbor Laboratory Press. 1989.

15. Leiker DL, McDougall AC. Technical guide for smear examination for leprosy by direct microscopy. Amsterdam, Leprosy Documentation Service. 1983.

16. Jopling WH, McDougall AC. Handbook of leprosy, 4th edn. Oxford, Heinemann Medical Books. 1988.

17. Sritharan V, Barker RH. A simple method for diagnosing M. tuberculosis infection in clinical samples using PCR. Mol Cell Probes 1991; 5: 385-395.

18. Clark-Curtiss JE, Jacobs WR, Docherty MA, Ritchie LR, Curtiss R. Molecular analysis of DNA and construction of genomic libraries of Mycobacterium leprae. J Bacteriol $1985 ; 161 ; 1093-1102$

19. Ridley DS, Jopling WH. Classification of leprosy according to immunity-a five group system. Int $J$ Lepr 1966; 34 : 255-273.

20. Buck GE, O'Hara LC, Summersgill JT. Rapid, simple method for treating clinical specimens containing Mycobacterium tuberculosis to remove DNA for polymerase chain reaction. $J$ Clin Microbiol 1992; 30: 1331-1334.

21. Panaccio M, Lew A. PCR based diagnosis in the presence of $8 \%$ (v/v) blood. Nucleic Acids Res 1991; 19: 1151.

22. Rao PS, Ekambaram V, Reddy BN, Krishnamoorthy P, Kumar SK, Dutta A. Is bacteriological examination by skin smear necessary in all paucibacillary leprosy patients in mass control programmes? Lepr Rev 1991 ; 62: 303-309.

23. Odinsen O, Nilson T, Humber DP. Viability of Mycobacterium leprae: a comparison of morphological index and fluorescent staining techniques in slit-skin smears and M. leprae suspensions. Int J Other Micobact Dis 1986; 54: 403-408.

24. Gillis TP, Williams DL. Polymerase chain reaction and leprosy. Int J Lepr Other Mycobact Dis 1991 ; 59: 311-316.

25. Shankara KM, Bedi BMS, Kasturi G, Kirchheimer WF, Balasubrahmanyan M. Demonstration of Mycobacterium leprae and its viability in the peripheral blood of leprosy patients. Lepr Rev 1972; 43: 181-187. 